\title{
THE BEST PRACTICE OF TEACH COMPUTER SCIENCE STUDENTS TO USE PAPER PROTOTYPING
}

\author{
Dave Miller \\ Principal Research Manager, NZQE, Auckland, New Zealand, Dave.miller@nzqe.ac.nz
}

\begin{abstract}
The importance of understanding the repercussions of effective user interface (UI) design is critical for future Computer Science (CS) professionals, given the ubiquity of interfaces on computer devices. Through a paper prototyping activity, this article explains how to teach rapidly and successfully CS students about "fit," a Human-Computer Interaction (HCI) concept. Despite its simplicity, the concept of "fit" can be difficult to grasp without much practice. In practice, designing "fit" into UIs can be prohibitively expensive because workable prototypes are generally beyond the technical capabilities of students. As a result, we illustrate how to use paper prototyping to demonstrate "fit" in a hands-on class exercise based on active learning concepts. To guide students through the process of "fit" in UI design, we provide extensive step-by-step directions for planning, setting up, and presenting the exercise. Students will be better equipped to apply both theoretical and practical applications of "fit" in UI design and execution as a result of this assignment; this exercise can be used in any course that covers user interface design, such as concepts of human-computer interaction, systems analysis and design, software engineering, and project management.
\end{abstract}

Keywords: Paper Prototyping, Best Practice, Computer Science, Students To Use of Teach. 


\section{INTRODUCTION}

Given the prevalence of computing devices in practically every part of our lives, how people interact with these devices is vital to all computing fields. In fact, failing to account for interface usability can result in a variety of issues ranging from minor annoyances to outright disasters. Common computing interfaces, such as Windows, Apple devices (particularly Apple Watch and Apple Maps), Smart TVs, and social media, have been noted as having poor usability (Ahmad, Al-Sa'di, \& Beggs, 2020; Al-Sa'di, 2018; Burton, 2016; Pogue, 2016). Poor design, apart from small annoyances, can have devastating repercussions. For example, in 1988, the US Navy shot down an Iranian civilian jet owing to a poor visual display (Pogue, 2016); while in 2003, Space Shuttle Columbia burned up upon re-entry, partly due to a poorly designed PowerPoint presentation (Park, 2015).

The study of "how humans engage with technology for a variety of reasons" is known as Human-Computer Interaction (HCI) (Zhang and Li, 2005, p. 228). The core phenomenon of interaction is the user interface (UI), which integrates human objectives with computing resources. The practical goal of HCI is to "provide high usability for users of computer-based systems" (Hartson, 1998, p. 103). In connection to a goal or desired outcome, usability is defined as the amount of satisfaction, efficiency, and effectiveness that an information system (or its components) provides to a user (Al-Sa'di, 2018; International Organization for Standardization, 1998). To build and assess "better, more effective" technologies (Cooper et al., 2014, p. XXIII) that minimise dissatisfaction (or even disaster) and encourage well-being, it is critical to understand how people's talents and limits affect interface usability. While people who work in the field of information systems (IS) should know better, given the prevalence of badly designed interfaces, all computer professionals might benefit from learning more HCI ideas.

Chan, Wolfe, and Fang (2002) emphasise the importance of teaching HCI and usability-related issues in IS, claiming that graduates must have a complete grasp of these topics. Working alongside developers to build efficient and effective systems, for example, CS students must grasp how crucial UI design is, as well as how to choose and appraise current tools to "fit" and facilitate operations. As a result, students should learn basic HCI concepts through training that allows them to practise "methods and skills to grasp present users, experience non-use, and imagine future users" (Faiola, 2007). (Churchill, Bowser, and Preece, 2016, p. 70). Practical 
training in UI design and assessment, on the other hand, is frequently overlooked. HCI, for example, is solely an option in the 2010 CS Model Curriculum (Janicki, Cummings, and Healy, 2015).

The empathic element of systems design and implementation is perhaps not one of the more notable aspects of the CS curriculum, with a significant focus on technical features of technology and other essential business-oriented topics such as project management (Al-Sa'di \& Parry, 2017). The interaction between designers and users may be mentioned in passing during the requirements engineering and validation phases of the systems development life cycle, but HCI concepts like UI design are unlikely to be stressed to, let alone practised by, students (Al-Sa'di, Parry, \& Carter, 2014). As a result, we are concerned that many CS students have a poor understanding of basic usability concepts, and that professors have little opportunity to teach them.

A mandatory 100 or 200-level HCI course would be beneficial in an ideal CS degree programme; however, we acknowledge that this is not always possible (especially in light of the Model Curriculum).

To that end, we present a problem-based scenario activity in which students create and test paper-based UI prototypes. The activity includes aspects of both designs (requiring reflection on HCI concepts) and implementation (through role-play that highlights how users employ these designs) in which students create and test UI prototypes (Al-Sa'di, Parry, \& Carter, 2018).

Students were expected to perform the exercise during an HCI class without the use of outside materials such as textbooks or digital sources in our implementation. We imposed these limitations in order to encourage consistency and creativity, as students could only use their own knowledge and ideas. While these circumstances fitted our learning aims for the specific class (mainly due to the notion of "fit" that we discuss later in this paper), we propose that other teachers modify this exercise as appropriate.

Given the limited resources and time restrictions that many teachers experience, our activity may be utilised at any point in the CS curriculum, from Introduction to MIS to Advanced Systems Analysis and Design - everywhere students need to learn and apply usability concepts. Students do not need any prior technical abilities, such as coding or wire-framing, to 
put up this project because the resources are readily available (e.g., paper and pens). As a result, the activity is widely available, and the materials are very affordable when compared to the hardware and software resources required to create a working digital prototype. This activity can be simply customised for any CS course and may be used to get K-12 children excited in computing. We describe how it was used in an introductory HCI course to underscore the significance of usability in this article.

\section{BACKGROUND CONCEPTS}

This activity is based on the Constructionist pedagogical theory. This approach, according to Papert (1991, p. 2), "boils down to asking that everything be understood by being made." The core premise is that when students create artefacts, they apply theory, concepts, and ideas in a way that is meaningful to them, making them active participants in their own learning. In other words, they construct to comprehend.

Rather of acting as a "sage on the stage," the instructor becomes a facilitator who consults, clarifies, encourages, and supports students in need through this pedagogical perspective. We provide background knowledge on paper prototyping, the concept of "fit," and a few suggested prerequisite concepts to prepare students to maximise their learning from this activity, given the shortage of HCI training in CS curriculum, and for those instructors who wish to brush up on this subject.

Paper Prototyping

Most CS professors are aware with the notion of prototypes, but they may be less so with how to put them into practise in the classroom. A prototype may be thought of as a hypothesis in the form of a rough design for a problem, which is then put to the test by how consumers interact with it (Pernice, 2016). Prototypes may be used in software development to get user feedback while also saving money since "it's 100 times cheaper to make a change before any code has been written than it is to wait until after the implementation is complete" (Nielsen, 2003, para 6).

During the 1980s, IBM promoted paper prototyping, often known as low-fidelity prototyping (Rettig, 1994) or trash prototyping (Vijayan and Raju, 2011). It is "creating prototypes on paper 
and testing them with real users" in its most basic form (Rettig, 1994, p. 1). Despite their crude appearance, research has shown that the feedback they enable is of nearly equal quality and quantity to that provided by computer-based prototypes (Alkhaldi \& Al-Sa'di, 2018; Sefelin, Tscheligi, and Giller, 2003). Figure 1 shows an example of a paper prototype made by one of our students as a point of reference.

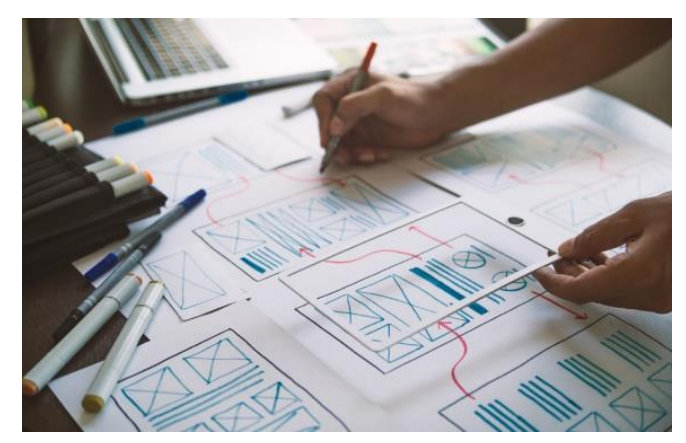

\section{Figure 1: Paper prototyping}

In the classroom, paper prototyping helps students to show their comprehension of fundamental topics by creating and evaluating fast, disposable user interfaces. This technique may be used to teach excellent design ideas like usability and "fit," as well as to assess understanding of these topics (lkhaldi \& Al-Sa'di, 2016). When students use paper prototyping, they create an interface, test it rapidly, and then remark on what worked and what didn't. Furthermore, using paper prototyping at various times in a lesson allows you to track students' understanding and progress throughout the semester.

\section{Key Concepts in Human-Computer Interaction}

In the field of human-computer interaction, usability is frequently characterised in terms of affordances and restrictions. Affordances are "design features of an object that imply how it should be utilised; a visual indication to its purpose and use" (Chamberlain, 2010, p.169; quoting Norman (1988)). and constraints are the "limitations of the activities that may be performed based on the appearance of the object" (Norman, 1988). For example, a keyhole's affordance is that the opening begs something to be entered; nevertheless, its limitation is that its tiny size and narrow breadth limit the range of what may be placed (Chandran, Al-Sa'di, \& Ahmad, 2020). A text field on a user interface, for example, encourages the user to enter character data (affordance), although its size and meta-properties might limit input possibilities 
to specific types and lengths of characters, such as a 4-digit pin number (constraint). In order to grasp "fit," students must first have a basic concept of affordances and restrictions.

Te'eni, Carey, and Zhang (2005) describe "fit" as a core notion in usability that is defined based on three distinct but connected dimensions: physical fit, cognitive fit, and affective fit. The input/output mechanics of technology in relation to human physiology are addressed by physical fit. This idea is like ergonomics and, to a lesser extent, accessibility. Physical fitness, in theory, should reduce physical effort while increasing output (Te'eni, Carey, and Zhang, 2005). Users may execute tasks successfully and efficiently when the UI and its feedback mechanisms are congruent with their past experiences, skill sets, and mental models. "The issue representation and the task both stress the same sort of information," in other words (Vessey and Galletta, 1991, p. 67). Finally, affective fit evaluates how functional (an item that a user interacts with) or non-functional (non-interactable features such as colour, typeface, etc.) UI design attributes might impact positive affect, negative affect, or another desirable emotional state (Avital and Te'eni, 2009). The purposeful design of affordances and limitations is sometimes (but not always) used to show these three sorts of "fit."

Paper prototyping, as a Constructionist exercise, allows students to experience establishing affordances and restrictions before experimenting with the many aspects of "fit." We embedded our activity's difficulty into a framework that would inspire learners to reflect, particularly on users' prospective physical, cognitive, and emotive states, to reinforce this link between the activity and the three components of "fit."

\section{PAPER PROTOTYPING ACTIVITY}

For two study semesters, we repeated this practise twice every semester (the justification for which is explained in the next section). Each execution of the exercise is designated Exercise Iteration 1 (EI1) and Exercise Iteration 2 (EI2), and each semester is designated Term 1 (T1) and Term 2 (T2) (T2). Because each iteration resulted in a paper prototype, each student received two prototypes every semester. Prototype Version 1 (PV1) and Prototype Version 2 (PV2) are the terms we use to describe these prototypes (PV2).

We began each iteration by showing a brief video of a testing session to introduce (or reintroduce) students to paper prototyping. In the video, one person interacts with the prototype 
(as a user) while another manipulates bits of paper (as a computer) (Sarsam, Al-Samarraie, \& Al-Sadi, 2020; Yun, 2007). The students were then given the task of designing a device interface utilising paper-based, hands-on materials. They were told there would be no grades, but they would be required to participate. The following rules were developed based on Snyder's (2001) guidelines:

- After the prototypes were completed, students were to form pairs.

- While in the "computer" role, a student presented his or her prototype to the "user"

- The "user" could click/tap on paper objects with his or her fingers while the "computer" manipulated the prototype accordingly to simulate interface behaviour

- The "user" could simulate inputting character text however they wanted (pretending to type, speaking/voice, selecting an option)

- The "computer" was not permitted to talk or make gestures indicating how to utilise the prototype; their job was limited to simulating or facilitating operation.

Students were then shown a PowerPoint slide (Figure 2) with instructions to design an urgent care check-in kiosk. 


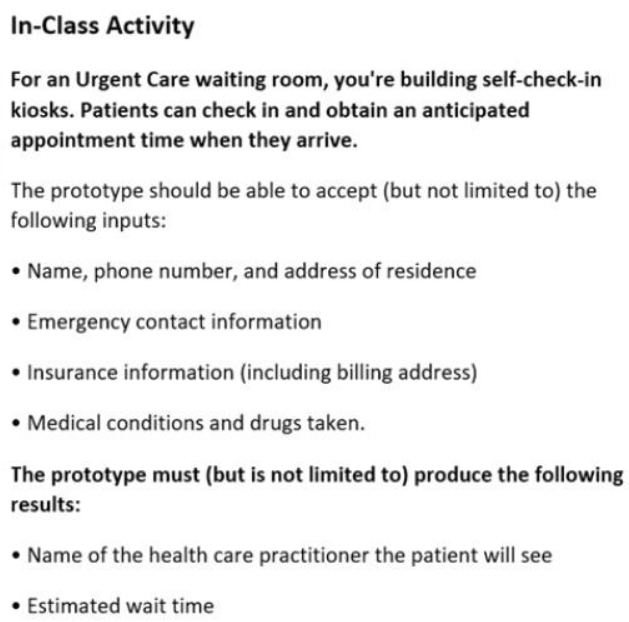

\section{Figure 2:In-class Activity}

We found the following materials to be sufficient for our needs, however amounts may vary depending on class size: Sticky notes and/or labels, index cards (x100), no. 2 pencils with erasers (plus extra erasers), coloured pencils, scotch tape, glue sticks, paper clips, binder clips, and scissors. $11 \times 17 "$ cardstock paper, $8.5 \times 11 "$ printer paper, $3 \times 5$ " notepad paper, sticky notes and/or labels, index cards (x100), no. 2 pencils with erasers (plus extra erasers), coloured pencils, scotch

Although students were not informed which materials to use to prevent accidentally influencing their designs, instructors should be aware of several typical practises. Due of its sturdiness, card stock was frequently used to portray major "screens." Sticky notes were useful for huge buttons or dialogue boxes, and scissors were useful for changing the sizes and forms of screen elements. Colored pencils helped distinguish things on the "screen" by highlighting them.

Students spent roughly 55 minutes working on their prototypes throughout the course hours in which our activities were done, during which time the teacher mediated and observed how the activity played out, helping and encouraging students as required. After that, students alternated playing the roles of computer and user with numerous peers. Each couple tested their prototypes for around five minutes before forming fresh pairings to test them again. During EI1 of T1, role-playing was restricted to the remaining class time, limiting students' ability to interact with a diverse group of peers. Prototype testing was relocated to the following class session in T2, providing for 40 to 45 minutes of testing time. The updated activity's timeframe 
is summarised in Table 1. Our schedule is based on two 75-minute classes, but it may easily be changed to three 50-minute sessions.

Table 1: Lesson Schedule of Paper Prototyping Activity

\begin{tabular}{|c|c|}
\hline Activity Steps & $\begin{array}{l}\text { Approximate } \\
\text { Duration }\end{array}$ \\
\hline \multicolumn{2}{|l|}{ Class Period \#1 } \\
\hline $\begin{array}{l}\text { Step 1: Introduction } \\
\text { Play a sample video, explain the issue, and give students time to gather materials and equipment } \\
\text { (scissors, pencils, tape, etc.) }\end{array}$ & 5-10 minutes \\
\hline $\begin{array}{l}\text { Step 2: Construct Prototype } \\
\text { Students construct prototypes on their own with limited assistance from the teacher. }\end{array}$ & $\begin{array}{l}55-60 \\
\text { minutes }\end{array}$ \\
\hline $\begin{array}{l}\text { Step 3: Construction Wrap-Up } \\
\text { Students finish prototypes and return toolsand unused materials }\end{array}$ & 5-10 minutes \\
\hline \multicolumn{2}{|l|}{ Class Period \#2 } \\
\hline $\begin{array}{l}\text { Step 4: Computer/User Roleplay Students team up with different classmates several times to } \\
\text { play "user" (testing a peer's prototype by simulating how they would interact with a digital version } \\
\text { of the design) and "computer" (manipulating their own prototypes based on the "user's" } \\
\text { interaction to simulate how it would behave as a digital artefact). }\end{array}$ & $\begin{array}{l}40-45 \\
\text { minutes }\end{array}$ \\
\hline $\begin{array}{l}\text { Step 5: Class-Wide Discussion } \\
\text { The instructor leads reflective discussionabout the activity }\end{array}$ & 30 minutes \\
\hline
\end{tabular}

Students were taken through a 30-minute face-to-face conversation after role-playing to reflect on and communicate what they learned, as well as to appreciate the importance of their experience. We did not provide students access to their PV1 before or throughout the construction of PV2 to verify that they were just using their current understandings of "fit." They were, however, permitted to go through both PV1 and PV2 following the role play portion of EI2 to make sure they were well-informed enough to talk about their paper prototyping experiences.

The questions we posed to foster this dialogue are listed below. Questions 1, 2, and 5 can be asked at any time during the exercise, whereas 3 and 4 should be asked after EI2.

1. What elements affected the design of your first prototype? To put it another way, why did you create your prototype the way you did? Students frequently cite prior experiences as (at least part of) the inspiration for their work. Instructors should question students about why such designs succeeded in prior UIs and whether or not they are still relevant for this challenge. 
2. Did the "usability tests," whether on your prototype or on a peer's prototype, teach you anything useful? This emphasises the importance of feedback in UI design, as students uncover beneficial methods that their classmates employed that they hadn't considered.

3. Describe any changes you made to your redesigned prototype, as well as why you made them. This stresses how information, iterative design, and assessment may help to enhance and inform "fit." The instructor should now challenge them to explain what they modified to improve the "fit" of their design.

4. Do you have any ideas for a third prototype that you didn't think of in the prior iterations? This encourages students to think about and reflect on features and functions that they were unable to implement owing to time restrictions, material limits, or other constraints (s).

5. What did you learn from this activity, if anything? This is meant to let students take a step back and consider how much significance they discovered in prototyping, design, and assessment. This encourages debate on how designer goals do not always align with user expectations, emphasising the value of prototyping and testing.

\section{EVIDENCE}

We ran two iterations of the exercise (one at the beginning and one at the conclusion of the semester) to see how much students' application (and hence assumed comprehension) of "fit"related concepts changed. Despite the fact that this is not a research study, we have proof that paper prototyping is successful. As a result, we provide our insights from both T1 and T2 in this section, as well as synthesise pertinent student comments from focus groups and course assessments.

\section{Instructor Observations}

As predicted, the majority of the work generated for EI1 in both terms did not reflect anything about the background of the problem. Although a few students evaluated potential physical restrictions, most students did not account for the user's probable physical, psychological, or emotional states at an urgent care clinic. Despite having an injury or condition that might limit movement, most PV1s required data to be entered via touch-based devices (such as a digital 
keyboard) or a mouse. A standard keyboard and mouse Meanwhile, PV1 showed some indication of affordances as functional hints (typically considered a measure of cognitive "fit").

After learning about the many forms of "fit," design concepts, and evaluation methodologies, students participated in EI2 during the last week of class. In general, pupils in PV2 showed a greater knowledge of the problem's background. Multiple kids' work demonstrated an accelerated check-in procedure, which was a considerable improvement. Users might, for example, supply important information later or request quick, emergency assistance on some prototypes. By speeding up the check-in procedure, these choices should lessen physical exertion, cognitive strain, and/or anxiety.

Another typical innovation was rapid input to reduce physical effort, such as dialogue windows for selecting nation and state (rather than having to write them out) or using an external reader to swipe one's insurance card (which would automatically populate related fields). Furthermore, students in the EI1 discussion leant significantly on prior experiences to express what affected their ideas; in the EI2 discussion, they did so as well, but were considerably more likely to frame their comments within the three dimensions of "fit."

\section{Focus Group and Course Survey}

Following EI2 of T2, a 30-minute focus group was convened during class time without the presence of the teacher to obtain honest, frank input from students to gain insight into their experiences. This was conducted by a colleague outside of the author's department in the hopes that students would feel comfortable being themselves with her.

According to one student, after taking this course,

"Every time I use any kind of technology or interface and come across something that I don't believe works or looks good, I'm going to remember what we learned and what I might do to repair it or improve it for someone, whether it's a website, an operating system, or anything else. I'll always find minor things I don't like about it now that I know how to do things correctly. So, I believe that will be the case for quite some time." 
"Which activities or tasks did you think were the most beneficial or important?" they were asked. a different student replied

"Prototyping, I believed, was the most informative, especially at the beginning, because it established the tone for the session and gave us a sense of what we'd be learning about. The prototyping at the end also provided us with a concrete representation of our development and what we learnt during the course."

"Cognitive fit, affective fit, and bodily fit...," one student said when asked what they would remember about the course in five years. That is not something I believe can be easily forgotten. Because you think about those things, but now that we have the technical terminology for them and what to search for, we can really look for them."

Finally, during the first semester, students gave the course an average rating of 5.5 out of 6 (81.2 percent response rate; $n=13)$ and 5.6 (82.4 percent response rate; $n=14)$.

We use these end-of-semester course assessments as at least partial evidence of the exercise's utility and success. This conclusion is based on the fact that paper prototyping was the most popular exercise in class, and it was meant to incorporate all of the course's primary themes.

Although the three dimensions of "fit" were not introduced until after the EI1 (around the third week of class), the course's first few lessons focused on usability in general, with the goal of introducing basic concepts like affordance and constraint in order to establish a foundation of vocabulary for the subsequent lessons on "fit." The next 6-7 weeks were devoted to "fit," with the remaining weeks devoted to computer-assisted cooperative work, ethical design, and usability testing methodologies. The importance of "fit" was emphasised throughout these sessions.

Given that our prototyping exercise was designed to elicit designs that account for "fit," given that "fit" is a cornerstone of our HCI course and given that the exercise was used as bookends around the majority of our classes, we believe that the focus group and course evaluation results can provide complementary, albeit anecdotal, evidence to support the degree to which paper prototyping succeeded. 


\section{DISCUSSION}

If you're thinking about using paper prototyping in your classroom, we have a few options that aren't included here. We begin by discussing other alternative courses in which paper prototyping may be used, followed by some basic recommendations for putting it into practise, and lastly, some extra student-oriented concerns.

\section{Other Potential Subjects for Adaptation}

Over the course of two semesters, we piloted this experiment in an Introduction to HCI elective course. Students in this class were Computer Science and/or Information Systems majors or minors. We feel that this exercise would be relatively productive in any course that touches on usability or interface design, based on the evidence of success mentioned in the preceding section and the authors' teaching skills. For example, when covering Design and Implementation as a phase in the Systems Development Life Cycle, this activity may be used in a Systems Analysis and Design course (SDLC). Prototypes, in particular, are mentioned as one design tool for assessing usability and making improvements after gathering and organising requirements in the Planning and Analysis phases (Sarsam et al., 2021; Valacich and George, 2017).

Students might be given functional and non-functional criteria and then asked to develop and test paper prototypes as part of an exercise. Not only may such an exercise help with practising and understanding usability ideas, but it could also lead to new insights on the need of clear and non-conflicting requirements documentation. Furthermore, it might emphasise that the SDLC is a unified process rather than a series of discrete phases.

A variant of this activity, for example, may be used in a Project Management (PM) course. Typical subjects in PM include SWOT analysis and feasibility evaluations, which are used to determine benefits and risks. Prototyping can be used to test the strengths and limitations of a software-based solution or as a rough draught to assess the technical (and financial) viability of building and deploying the system.

Furthermore, we feel that this exercise gives valuable knowledge that can be used throughout the whole IS curriculum, and that it might be utilised to teach HCI principles in a MIS 101 
course. Students may understand that human-based interactions (such as collaborative connections, trust, and social capital (Skammelsen, Xiang, Aakarsh, \& Kuppusamy, 2020; Kumar, van Dissel, and Bielli, 1998)) are typically crucial to IS design and implementation through role-playing computer and user. To put it another way, the activity might highlight the importance of contact between IT experts and end users.

\section{Tips for instructor}

Although we created and implemented our prototype exercise with the purpose of students working autonomously, we discovered that minimal teacher involvement benefited them. We propose that, while the instructor is supposed to be a facilitator, he or she does not have to be a mute observer, which is in line with Constructionism. During the creative process, students might be motivated by praise or gently critical support. Comments like "oh, you're not using coloured pencils?" or "what does this mean?" might pique students' interest or encourage them to relate the activity to course material.

In addition, the instructor's insights are useful in the discussion that follows the exercise. The teacher can find typical misconceptions or chances to discuss with the class by watching what students do during the exercise in both of the roles provided. If a crucial construct isn't seen as a design feature, for example, this might indicate that the build needs to be defined or enhanced in a following lesson or activity.

Finally, during testing times, the teacher should remind students (and correct conduct) if the rules for the roles of "computer" and "user" are not followed correctly. Because the "computer" depicts and manipulates their own design, it may be tempted to provide the "user" suggestions in the form of vocal explanations or non-verbal cues such as sighs, looks, or gestures. This is understandable since the student wants their prototype to succeed, and the functionality makes sense to them because they designed it from their own perspective.

We also didn't evaluate the activity since we wanted pupils to be as creative as possible and feel free to take risks rather than being constrained by a rubric's requirements. We believe that reminding the "computer" that this activity was not being graded helped to put them at ease and, as a result, they were less likely to provide the "user" hints. 


\section{Considering Different Contexts, Skillsets, and Tools}

We asked students to construct their prototypes in class because we wanted to guarantee that (1) the materials they used were consistent, (2) they did not collaborate with others, and (3) their work was not impacted by looking for and borrowing from comparable interfaces. The final two aspects, we considered, were critical in ensuring that students' artefacts reflected their own thoughts and understandings. However, mandating in-class design work meant that students who were unable to attend those sessions missed out on the opportunity to create an artefact, and that students' work was confined (or even hurried) due to a lack of class time.

We want to allow students to create their prototypes from home in the future, despite fears that they may conspire or use unapproved resources for advice. We believe the potential advantages will exceed the drawbacks since students will have more time to dwell on the challenge and consider possible solutions, which will allow them to express their creativity and usability perspectives. We will offer explicit instructions, as with every assignment, to alleviate our anxieties as much as possible, recognising that any implementation will have its own set of perks and cons.

Each term we used the exercise, there were around 15 students, virtually all of them were Juniors and Seniors in CS or Computer Science majors, with 2 or 3 students in each class who were Sophomores or minors in the aforementioned disciplines. This group was mostly conversant with the foundations of computing technology and had no reservations about the physical needs of using paper-based materials.

However, we acknowledge that this exercise presupposes that kids are physically capable of handwriting, sketching, and paper-based craftwork. Students with physical restrictions or less comfort might design their UIs with digital tools (such as PowerPoint or wireframing software) and then produce a printout to bring to class, given our notion that prototyping could happen from home.

Regardless of the tools and limits used in this exercise, one of the primary goals of paper prototyping is to produce a valuable learning experience that is accessible to almost everyone. As a result, regardless of a priori technical abilities or expertise, we urge teachers to conduct the activity in whichever way allows them to reach the greatest possible spectrum of pupils. 
Such "unplugged" activities have the potential to create democratised, meaningful opportunities for students in computing-oriented classrooms to gain knowledge across a spectrum of skill sets, expectations, and goals, regardless of major, colour, or gender.

\section{CONCLUSION}

We wrote about and remarked on our usage of a paper prototyping activity to teach the notion of "fit" in this article. While research has shown that paper prototypes can produce similar critical feedback in terms of quantity and quality to computer-based prototypes (Sefelin, Tscheligi, and Giller, 2003), there is little, if any, empirical work to guide CS instructors in using paper prototyping in the classroom to our knowledge.

We think that implementing and monitoring a paper prototyping activity across two terms of an HCI course is a realistic way for students to obtain hands-on experience applying ideas of "fit" to an artefact that can be shared and debated. Students may be more aware of the importance of people while building, deploying, and assessing information systems if they have a better grasp of "fit" and the practise of designing UIs based on that understanding. User concerns are crucial to successful and efficient interactions with hardware and software as computers becomes increasingly widespread in the industrialised world (Janicki, Cummings, and Healy, 2015)

As a result, CS curricula must continue to emphasise the importance of "fit" in successful UI design through instructional initiatives like the one described in this study.

\section{References}

[1].Ahmad, E., Al-Sa'di, A., \& Beggs, K. (2020). A Formative Assessment Framework Using Game-Quiz Educational Approach. Paper presented at the 2020 IEEE International Conference on Teaching, Assessment, and Learning for Engineering (TALE).

[2].Al-Sa'di, A. (2018). User interface guidelines for Tablet PC Arabic educational applications. (PhD). Auckland University of Technology, New Zealand.

[3].Al-Sa'di, A., \& Parry, D. (2017). Successful User-Centred Design for Tablet PC: A Conceptual Framework. Human IT: Journal for Information Technology Studies as a Human Science, 13(3), 89-114. 
[4].Al-Sa'di, A., Parry, D., \& Carter, P. (2014). Usability considerations for educational tablet applications using an Arabic interface. Paper presented at the 2014 5th International Conference on Information and Communication Systems (ICICS).

[5].Al-Sa'di, A., Parry, D., \& Carter, P. D. (2018). User interface preferences of young Jordanians using tablet devices. Int. J. Technology Enhanced Learning, 10(3), 202-217.

[6].Alkhaldi, A. N. (2016). The Impact of Demographic Factors on Arabic Users' Adoption of M-Banking in Saudi Arabia: A Review. International Journal of Knowledge and Research in Management and E-Commerce, 5(4).

[7].Alkhaldi, A. N., \& Al-Sa'di, A. (2018). Gender Differences in User Satisfaction of Mobile Touch Screen Interfaces: University Students' Service Sites. International Journal of Innovation and Technology Management.

[8].Alkhaldi, A. N., \& Al-Sa'di, A. (2016). Guidelines integrating cultural theories with technology acceptance theories: A review. NZJ Comput. Hum. Interact, 1, 12.

[9].Avital, M. \& Te'eni, D. (2009). From Generative Fit to Generative Capacity: Exploring an Emerging Dimension of Information Systems Design and Task Performance. Information Systems Journal, 19(4), 345-367.

[10]. Burton, G. (2016). Top 10 Worst User Interfaces. The Inquirer. Retrieved August 6, 2020, from

https://www.theinquirer.net/inquirer/feature/2459940/top- 10-worst-user-interfaces.

[11]. Chan, S. S., Wolfe, R. J., \& Fang, X. (2002). Teaching HCI in IS/EC Curriculum. In Proceedings of the Eighth Americas Conference on Information Systems (pp. 1011-1020). Dallas, Texas.

[12]. Chamberlain, P. (2010). Horses, Elephants and Camels. Challenges and Barriers to Interdisciplinary User-Centered Design Research. In DS 60: Proceedings of DESIGN 2010, the 11th International Design Conference (pp. 163-172). Dubrovnik, Croatia.

[13]. Chandran, S., Al-Sa'di, A., \& Ahmad, E. (2020). Exploring User Centered Design in Healthcare: A Literature Review. Paper presented at the 2020 4th International Symposium on Multidisciplinary Studies and Innovative Technologies (ISMSIT).

[14]. Churchill, E. F., Bowser, A., \& Preece, J. (2016). The Future of HCI Education: A Flexible, Global, Living Curriculum. Interactions, 23(2), 70-73. 
[15]. Cooper, A., Reimann, R., Cronin, D., \& Noessel, C. (2014). About Face: The Essentials of Interaction Design (4th ed.). Indianapolis, Indiana: John Wiley \& Sons.

[16]. Faiola, A. (2007). The Design Enterprise: Rethinking the HCI Education Paradigm. Design Issues, 23(3), 30-45.

[17]. Hartson, R. H. (1998). Human-Computer Interaction: Interdisciplinary Roots and Trends. Journal of Systems and Software, 43(2), 103-118.

[18]. International Organization for Standardization. (1998). Ergonomic Requirements for Office Work with Visual Display Terminals (VDTs) - Part 11: Guidance on Usability (ISO Standard No. 9241-11). Retrieved June 5, 2019, from https://www.iso.org/standard/16883.html.

[19]. Janicki, T., Cummings, J., \& Healy, R. J. (2015). Incorporating a Human-Computer Interaction Course into Software Development Curriculums. Information Systems Education Journal, 13(3), 81.

[20]. Kumar, K., van Dissel, H. G., \& Bielli, P. (1998). The Merchant of Prato-Revisited: Toward a Third Rationality of Information Systems. MIS Quarterly, 22(2), 199-226.

[21]. Nielsen, J. (2003). Paper Prototyping: Getting User Data before You Code. Nielsen Norman Group. Retrieved August 6, 2020, from https://www.nngroup.com/articles/paperprototyping/.

[22]. Norman, D. A. (1988). The Psychology of Everyday Things. New York, New York: Basic Books.

[23]. Papert, S. (1991). Situating Constructionism. In S. Papert \& I. Harel (Eds.), Constructionism: Research Reports and Essays, 1985-1990 (pp. 1-11). Norwood, New Jersey: Ablex Publishing Corporation.

[24]. Park, K. (2015). PowerPoint Should be Banned. This PowerPoint Presentation Explains Why. The Washington Post. Retrieved June 3, 2019, from https:// www.washingtonpost.com/posteverything/wp/2015/05/26/powerpoint-shouldbe-banned-this-powerpoint-presentation-explains-why . 
[25]. Pernice, K. (2016). UX Prototypes: Low Fidelity vs. High Fidelity. Nielsen Norman Group. Retrieved November 8, 2019, from http://www.nngroup.com/articles/uxprototype- hi-lo-fidelity.

[26]. Pogue, D. (2016). 5 of the Worst User-Interface Disasters. Scientific American. Retrieved May 28, 2018, fromhttps://www.scientificamerican.com/article/pogue-5-ofthe- worst-user-interface-disasters/.

[27]. Rettig, M. (1994). Prototyping for Tiny Fingers.

[28]. Communications of the ACM, 37(4), 21-27.

[29]. Sarsam, S. M., Al-Samarraie, H., \& Al-Sadi, A. (2020). Disease discovery-based emotion lexicon: a heuristic approach to characterise sicknesses in microblogs. Network Modeling Analysis in Health Informatics and Bioinformatics, 9(1), 1-10.

[30]. Sarsam, S. M., Al-Samarraie, H., Bahar, N., Shibghatullah, A. S., Eldenfria, A., \& AlSa'Di, A. (2021). Detecting real-time correlated simultaneous events in microblogs: The Case of Men's Olympic Football. Paper presented at the International Conference on Human-Computer Interaction.

[31]. Skammelsen, R. B., Xiang, Q. J. Y., Aakarsh, B., \& Kuppusamy, S. (2020). Usability Evaluation for User Interface Design of Student Support System: Mixed Method Study. Paper presented at the IOP Conference Series: Materials Science and Engineering.

[32]. Sefelin, R., Tscheligi, M., \& Giller, V. (2003). PaperPrototyping - What is it Good For? A Comparison of Paper-and Computer-Based Low-Fidelity Prototyping. In CHI'03 Extended Abstracts on Human factors in Computing Systems (pp. 778-779). Fort Lauderdale, Florida.

[33]. Snyder, C. (2001). Paper Prototyping: Sure, It's Low-Tech, But This Usability Testing Method Can Help You Sidestep Problems Before You Write Your Code. Retrieved November $\quad 9, \quad 2019, \quad$ from $\quad \underline{\text { https://www.csee.umbc.edu/ }}$ courses/undergraduate/345/spring12/mitchell/readings/pape rPrototyping_Snyder.pdf.

[34]. Te'eni, D., Carey, J. M., \& Zhang, P. (2005). Human-Computer Interaction: Developing Effective Organizational Information Systems. Hoboken, New Jersey: John Wiley \& Sons. 
[35]. Valacich J. S. \& George J. F. (2017). Modern Systems Analysis and Design (8th Ed). Upper Saddle River, New Jersey:Pearson Education, Inc.

[36]. Vessey, I. \& Galletta, D. (1991). Cognitive Fit: An Empirical Study of Information Acquisition. Information Systems Research, 2(1), 63-84.

[37]. Vijayan, J. \& Raju, G. (2011). A New Approach to Requirements Elicitation Using Paper Prototype. International Journal of Advanced Science and Technology, 28, 9-16.

[38]. Yun, C. (2007). Hanmail Paper Prototype. [Video] Retrieved July 30, 2018, from

https://www.youtube.com/watch?v=GrV2SZuRPv0.

[39]. Zhang, P. \& Li, N. (2005). The Intellectual Development of Human-Computer Interaction Research: A Critical Assessment of the MIS Literature (1990-2002). Journal of the Association for Information Systems, 6(11), 227-292.

[40]. Ali, N., Ghazal, T., Ahmed, A., Abbas, S., Khan, M., Alzoubi, H., Farooq, U., Ahmed, M. \& Khan, M. (2021) Fusion-Based Supply Chain Collaboration Using Machine Learning Techniques. Intelligent Automation \& Soft Computing, 31(3), 1671-1687

[41]. Ghazal, T., Hasan, M., Alshurideh M., Alzoubi, H., Ahmad, M., Akbar, S., Al Kurdi, B. \& Akour, I. (2021) IoT for Smart Cities: Machine Learning Approaches in Smart Healthcare-A Review, Future Internet, 13, 218. https://doi.org/10.3390/fi13080218

[42]. Ali, N., Ahmed, A., Anum, L., Ghazal, T., Abbas, S., Khan, M., Alzoubi, H. \& Ahmad, A. (2021) Modelling Supply Chain Information Collaboration Empowered with Machine Learning Technique. Intelligent Automation \& Soft Computing, 30(1): 243-257. DOI:10.32604/iasc.2021.018983

[43]. Analyzing the effect of knowledge management processes in the services' quality in Iraqi commercial banks. International Review of Management and Business Research, 5(1), 302-314. (2016)

[44]. Exploring the Impact of the use of Business Information systems BIS on the organizational performance effectiveness. International Journal of Business and Management Invention, 5(4), 48-55. (2016)

[45]. The Impact of Managers Efficiency on Quality of Strategic Decision-making under Crisis Management. European Journal of Business and Management, 7(26), 156-166. (2015) 
[46]. Investigating the Relationship between Knowledge Management Processes and Organizational Performance: The Mediating Effect of Organizational Innovation. International Review of Management and Business Research, 4(4), 977-997 (2015).

[47]. The Impact of Business Process Management on Business Performance Superiority. International Journal of Business and Management Review, 3(2), 17-34 (2015)

[48]. Evaluating Strategic Quality Management Dimensions Using Analytic Hierarchy Process (AHP) and its Impact on Organizational Success. International Journal of Research in Management, 5(1), 137-150 (2015)

[49]. American Muslims' Perceptions Toward Transforming Islamic Banking System. International Journal of Economics, Commerce and Management, 5(1), 1-16 (2015)

[50]. Exploring the Relationship between Quality Orientation, New Services Development and Organizational Performance. American Academic \& Scholarly Research Journal, 5(3), 315-329 (2013)

[51]. Analyze the Impact of Managers Awareness of Environmental Uncertainty on Exploiting Strategic Competencies. Egyptian Journal for Commercial Studies, 34(2), 611$625(2010)$

[52]. Applying Electronic Supply Chain Management Using Multi-Agent System: A Managerial Perspective. International Arab Journal of e-Technology, 1(3), 106-113 (2010)

[53]. Propose a model for Performance Criteria and measuring its impact for Achieving Excellence, Association of Arab Universities Journal, 56 (4), 920-941. (2010)

[54]. S. Y. Siddiqui, A. Haider, T. M. Ghazal, M. A. Khan, I. Naseer, S. Abbas, M. Rahman, J. A. Khan, M. Ahmad, M. K. Hasan, A. M. A, and K. Ateeq, "IOMT cloud-based intelligent prediction of breast cancer stages empowered with Deep Learning," IEEE Access, vol. 9, pp. 146478-146491, Oct. 2021.

[55]. S. Abbas, Y. Alhwaiti, A. Fatima, M. A. Khan, M. Adnan Khan, T. M. Ghazal, A. Kanwal, M. Ahmad, and N. Sabri Elmitwally, "Convolutional neural network based intelligent handwritten document recognition," Computers, Materials \& Continua, vol. 70, no. 3, pp. 4563-4581, Oct. 2021.

[56]. T. M. Ghazal, S. Abbas, S. Munir, M. A. Khan, M. Ahmad, G. F. Issa, S. Binish Zahra, M. Adnan Khan, and M. Kamrul Hasan, "Alzheimer disease detection empowered with transfer learning," Computers, Materials \& Continua, vol. 70, no. 3, pp. 5005-5019, Oct. 2021. 
[57]. N. Ali, T. M. Ghazal, A. Ahmed, S. Abbas, M. A. Khan, H. M. Alzoubi, U. Farooq, M. Ahmad, and M. Adnan Khan, "Fusion-based supply chain collaboration using Machine Learning Techniques," Intelligent Automation \& Soft Computing, vol. 31, no. 3, pp. 1671-1687, Oct. 2021.

[58]. M. K. Hasan, T. M. Ghazal, A. Alkhalifah, K. A. Abu Bakar, A. Omidvar, N. S. Nafi, and J. I. Agbinya, "Fischer linear discrimination and quadratic discrimination analysisbased data mining technique for internet of things framework for Healthcare," Frontiers in Public Health, vol. 9, Oct. 2021.

[59]. R. Bibi, Y. Saeed, A. Zeb, T. M. Ghazal, T. Rahman, R. A. Said, S. Abbas, M. Ahmad, and M. A. Khan, "Edge AI-based automated detection and classification of road anomalies in VANET using Deep Learning," Computational Intelligence and Neuroscience, vol. 2021, pp. 1-19, Sep. 2021.

[60]. M. Adnan Khan, T. M. Ghazal, S.-W. Lee, and A. Rehman, "Data Fusion-based machine learning architecture for intrusion detection," Computers, Materials \& Continua, vol. 70, no. 2, pp. 3399-3413, Sep. 2021. 